\title{
Toward Cleaner Production technologies in surface treatment of metals
}

\author{
A. Nakonieczny \& M. Kieszkowski \\ Institute of Precision Mechanics, Warsaw, Poland
}

\begin{abstract}
Cleaner Production technologies are an efficient tool to solve the environmental problems of the surface treatment of metals with a number of process-integrated and end-of-pipe techniques and to minimise emissions to the waters and to air, as well as to reduce the generation of hazardous wastes. This paper presents a short characteristic of the main environmental problems of surface treatment of metals with special consideration of hazardous wastes generated in the production of the corrosion-protective and decorative coatings. Key environmental issues are given. General principles of Cleaner Production technologies for surface treatment processes are discussed. Some practical methods of reducing water consumption and different techniques of the direct recovery of process solutions are shown. Practical examples of Cleaner Production methods implemented into Polish plating shops for zinc, nickel, chromium and tin plating are presented with a short description of the obtained efficiency of recovery and economy of water consumption.

Keywords: surface treatment of metals, environmental protection, Cleaner Productions, IPPC Directive, rinsing technology, water consumption, emissions minimisation, recovery of process solutions.
\end{abstract}

\section{Introduction}

Cleaner Production [1] technologies are among the main elements of the Best Available Techniques, which have to be implemented in plating shops to obtain the new integrated permit, according to European Directive 96/61/EC, so called IPPC Directive [2] (IPPC = Integrated Pollution Prevention and Control).

The strategy of Cleaner Production and Best Available Techniques are both based on the application of low-waste and waste-free technologies. Also the 
priorities of environmental protection measures of the Best Available Techniques are similar to Cleaner Production methods and are based usually on three types of activities [3]:

- elimination of sources of toxic emissions

- $\quad$ substitution of harmful substances by environmentally friendly ones

- minimisation of wastes which are difficult to eliminate.

\section{Key environmental issues}

Key environmental issues in the surface treatment industry are: raw materials, energy and water usage, emissions to water and to air, as well as generation of liquid and solid wastes. Therefore efforts to reduce environmental impacts of production activities in this sector are directed mainly at:

- efficient and economic usage of raw materials, energy and water

- minimisation of emissions by effective process control and waste water treatment

- minimisation of generated wastes

- prevention of environmental accidents with an effective protection of soils and groundwater with a view to future site decommissioning.

Technological and management measures to achieve better environmental protection are often complex and cover a variety of process-integrated and endof-pipe techniques. As the majority of surface treatment processes are waterbased, the water usage and its management with associated raw materials consumption, waste water treatment technology and waste generation are the most important issues. Key emissions to water are typically metals, which are used as soluble salts and, depending on the process, may include zinc, nickel, chromium, copper and other. Waste water may also contain many other species, including cyanides, surfactants, complexing agents (as e.g. EDTA) and different anion, like chlorides, sulphates, phosphates, nitrates etc.

Therefore, the production of metal platings for protective and decorative purposes generates waste water, solid wastes and smaller quantities of some volatile impurities:

$\Rightarrow$ waste water which may contain various hazardous compounds, such as metals, cyanides and some mineral acids, alkalis, mineral salts, oils, organic substances and other

$\Rightarrow$ solid wastes and concentrated liquids consisting mainly of neutralisation sludge and spent process solutions

$\Rightarrow$ volatile impurities, such as hydrogen chloride, sulphur dioxide, nitrogen oxides, aerosols, dust and other volatile substances which may be emitted to the atmosphere during technological processes.

\section{General principles of Cleaner Production technologies}

General principles and main elements of cleaner technologies for surface treatment processes are: 
- reduction of any risk of environmental accidents resulting in unplanned emissions to the environment

- modifications of technological processes - substitution options for various harmful chemicals and processes, such as organic solvents (especially chlorinated hydrocarbons), EDTA and other strong chelating agents, cadmium, hexavalent chromium, nickel and others

- regeneration and other maintenance operations to extend the life of process solutions and to avoid or to reduce their dumping frequency, or to improve bath performance

- minimisation of drag-out of process solutions (specifically in rack and barrel lines)

- efficient and economic rinsing technology ("eco" rinse, multistage cascade rinsing, multistage static rinsing, minimisation of rinsing water consumption etc.)

- direct recovery of process baths (evaporation and other methods of rinsing water concentration, closed loop of materials)

- energy saving (electricity, bath heating, cooling, bath agitation)

- waste water (flow minimisation, identification and separation of problematic flows, waste water treatment technology)

- waste management

- air emissions.

\section{Direct recovery of process solutions}

Direct recovery of plating baths is based on the proper utilisation of effective and economic rinsing techniques. It consists of increasing drag-out recovery by returning the rinse water from the first rinse to the process solution. It is a good example of Cleaner Production technology with technical and economic advantages such as:

$\Rightarrow$ higher quality of plating

$\Rightarrow$ lower consumption of rinsing water

$\Rightarrow$ reduction of volume and load of generated waste water

$\Rightarrow$ reduction of waste water treatment cost

$\Rightarrow$ reduction of neutralisation sludge volume

$\Rightarrow$ improvement of final effluent quality.

In the simplest case, the direct recovery of plating baths is realised with a static, so called drag-out tank (economic rinse), which is commonly used after high temperature process baths. Rinse water from drag-out tank is used for the replenishment of volume losses of the process bath due to evaporation. Periodic water transfer from drag-out tank into process tank is made with a small pump. Practical recovery ratio obtained by this method is usually not higher than 50-60 $\%$. Efficiency of the direct recovery can be significantly improved by the application of several drag-out tanks, arranged in series. Such a technique is successfully applied in the WK-1 automatic drag-out recovery system, developed at the Institute of Precision Mechanics in Warsaw. Schematic diagram of this system is shown in Fig. 1. 


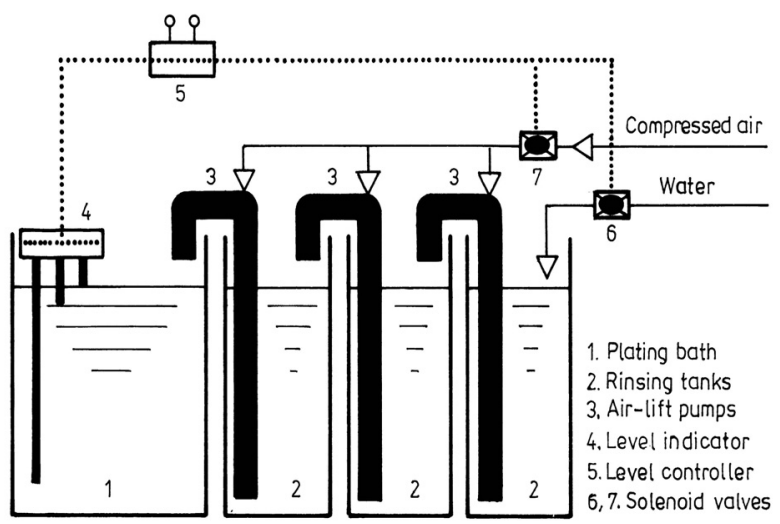

Figure 1: $\quad$ WK-1 direct recovery system of plating baths.

Air-lift pumps made from PVC (3) are used for water transfer from one rinse tank (2) to another and from the first rinse tank to the process tank (1). Fresh water feed into the rinsing system and the operation of air-lift pumps are automatically controlled by solenoid valves (6) and (7). Opening and closing of both valves is controlled by an electronic level controller (5) coupled with conductometric probes of a level indicator (4) installed in the process tank (1). Demineralised water should be used to feed the WK-1 drag-out rinse tanks. Special construction of air-lift pumps makes possible the transfer of only the excess of water entering the rinse tank (as an overflow) and thus to maintain the same and constant water level in the rinse tanks. Normally the consumption of low pressure air to operate WK-1 air-lift pumps is in the range of $30-50 \mathrm{~m}^{3} / \mathrm{h}$. Depending on plating line output, evaporation losses of the bath, free room available at the plating shop etc., 3-4 or more drag-out tanks in series are normally installed. They can work in a closed loop system, i.e. practically with no effluent. Application of air-lift pumps of proper construction enables the creation of a multistage counter-flow (cascade) drag-out tank system, using individual rinse tanks without any design modifications, such as pipe fittings, overflows etc. It helps to simplify the implementation work and to reduce its cost. The WK-1 system has been installed in many plating shops in Poland and abroad, mainly for nickel, tin and copper plating baths and other hot bath recovery systems with an efficiency of 85-95\%. It has been also used for the recovery of process solutions operating at room temperature, such as zinc plating baths. In this case a small atmospheric evaporator is frequently installed to work in co-operation with the WK-1 system.

In case of chromium plating, where relatively small size process tanks are commonly in use, a good recovery rate is rather difficult to achieve, even with the WK-1 system. For this bath the IMPCHROME evaporator has been developed (Patents 149.478 PL and 149.479 PL). Partial evaporation of chromium bath enables the introduction of more rinse water into the plating tank and thus the improvement of the recovery efficiency. 
The IMPCHROME evaporator comprises tubular modules made of PVC, in which evaporation occurs due to the action of low pressure air supplied from the central factory system or from an independent blower. The evaporator has no heating elements - the necessary heat energy is supplied by the hot bath. Because of the exothermic character of chromium plating process, the waste heat is used for evaporation. Therefore the chromium bath does not require any additional cooling system and the energy cost of the recovery process becomes very low. The consumption of low pressure air $(0.02-0.04 \mathrm{MPa})$ is normally of the range of $200-300 \mathrm{~m}^{3} / \mathrm{h}$. The plating bath is continuously circulated between the plating tank and IMPCHROME evaporator. The WK-1 system ensures the replenishment of plating bath with rinsing water transferred by automatically operated air-lift pumps. Schematic diagram of this system is shown in Fig. 2.

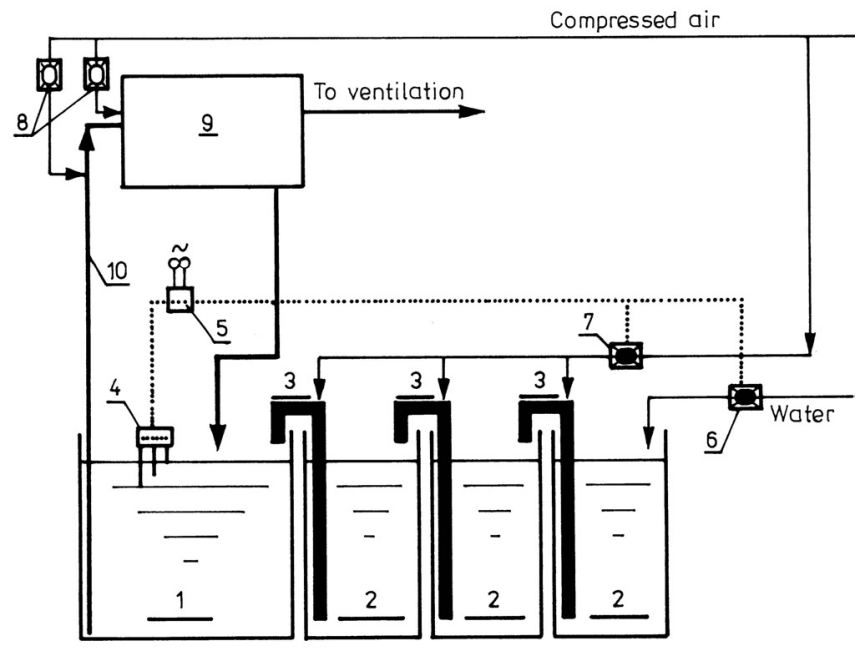

Figure 2: Direct recovery system of chromium plating bath using IMPCHROME evaporator (1.Cr plating bath; 2.Rinsing tanks; 3.Air-lift pumps of WK-1 system; 4.Level indicator; 5.Level controller; 6,7.Solenoid valves; 8.Correction valves; 9.IMPCHROME evaporator; 10.Air-lift pumps for Cr-plating bath).

\section{Practical examples of implemented techniques}

Schematic of the modified semi-automatic barrel zinc plating line, installed at a plating shop in Poland, replacing a prior non-linear tank arrangement, is shown in Fig. 3. In this line, several cleaner technology elements were implemented, such as:

- 4-step counter-flow drag-out tank (8/9/10/11) for rinsing after five zinc plating tanks (7) equipped with an automatic WK-1 system for zinc bath recovery 
- atmospheric evaporator located under the line, to assist and to improve recovery efficiency

- inter-connected 2-step counter-flow rinse tanks (2/3) and (5/6), where the same water is used twice - for rinsing after acid-dip (4) and finally after electrolytic degreasing (1)

- 2 -step counter-flow rinse tank (13/14) after zinc passivation bath (12)

- flow-meters and water-counters in the rinse tanks

- micro-filtration unit for the purification and regeneration of degreasing bath. A small RO unit for demineralised water supply is also installed.

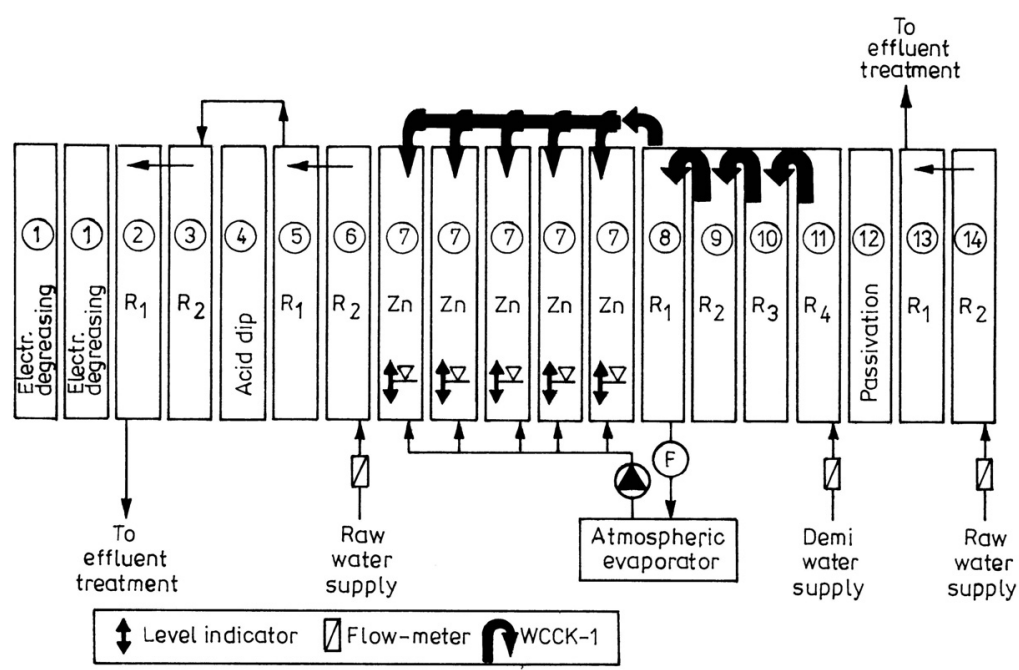

Figure 3: Schematic diagram of the modified semi-automatic barrel zinc plating line equipped with cleaner technology elements.

With an average zinc plating output of $70.000 \mathrm{~m}^{2} /$ year, the main economic effects observed after installation of the line were:

- drag-out recovery ratio of Zn-plating bath was $98 \%$ (about $300 \mathrm{~kg} \mathrm{Zn/year),}$ which means that amount of zinc drag-out from plating baths into waste water and then precipitated as useless sludge has been reduced by a minimum of $98 \%$

- average water consumption for rinsing purposes was reduced to $18 \mathrm{l} / \mathrm{m}^{2}$. With the original water consumption of about $200 \mathrm{l} / \mathrm{m}^{2}$ it means a reduction ratio of $91 \%$

- other savings included reduction of energy cost of the plating shop and waste water treatment system operation, reduction of anodes and plating salt consumption, reduction of chemicals consumption for waste water treatment processes, reduction of sludge de-watering and disposal costs, reduction of environmental charges etc.

In another case, similar modifications, with the application of Cleaner Production elements, were made for a semi-automatic rack nickel-chromium 
plating line. 4-step counter-flow drag-out tanks equipped with WK-1 bath recovery systems located after Ni-plating and $\mathrm{Cr}$-plating baths were implemented together with an IMPCHROME evaporator for $\mathrm{Cr}$-plating bath recovery. With an average $\mathrm{Ni}-\mathrm{Cr}$ plating output of $28.000 \mathrm{~m}^{2} /$ year, a $99 \%$ drag-out recovery ratio of Ni-plating bath (about $330 \mathrm{~kg} \mathrm{Ni} /$ year) and $97 \%$ drag-out recovery ratio of Cr-plating bath (about $1250 \mathrm{~kg} \mathrm{Cr0} /$ year) were achieved. Water consumption was reduced to approx. $221 / \mathrm{m}^{2}$.

In yet another case a small manual tin plating line was modified. 3-step counter-flow drag-out tank with the WK-1 bath recovery system was applied. With an average Sn-plating output of $6.000 \mathrm{~m}^{2} /$ year, a $96 \%$ drag-out recovery ratio of Sn-plating bath (about $32 \mathrm{~kg} \mathrm{Sn} /$ year) was achieved. At the same time the rinsing water consumption dropped substantially.

Table 1 presents metal concentrations observed in the rinse tanks of the WK1 recovery systems installed in the modified plating lines after 3 months of operation.

Table 1: Average $\mathrm{Zn}, \mathrm{Ni}, \mathrm{Cr}$ and $\mathrm{Sn}$ concentrations in the rinse tanks of the WK-1 recovery systems applied to modified plating lines after 3 months of operation.

\begin{tabular}{|c|c|c|c|c|}
\hline & $\begin{array}{c}\text { zinc plating } \\
\text { line }[\mathrm{g} / \mathrm{l} \mathrm{Zn}]\end{array}$ & \multicolumn{2}{|c|}{ nickel-chromium plating line } & \multirow{2}{*}{$\begin{array}{c}\text { tin plating } \\
\text { line }[\mathrm{g} / 1 \mathrm{Sn}]\end{array}$} \\
\cline { 3 - 4 } & 28,6 & 80,2 & 157 & 36,5 \\
\hline plating bath & 1,27 & 5,60 & 34,1 & 2,0 \\
\hline $1^{\circ}$ rinse tank & 0,36 & 0,58 & 2,97 & 0,20 \\
\hline $2^{\circ}$ rinse tank & 0,018 & 0,15 & 0,21 & 0,01 \\
\hline $3^{\circ}$ rinse tank & 0,0036 & 0,006 & 0,007 & - \\
\hline $4^{\circ}$ rinse tank & & & \\
\hline
\end{tabular}

As can be seen, a very low concentration of metals in the last rinse tanks of WK-1 systems was noted, which proves good efficiency of the recovery technique applied.

\section{Conclusions}

Various Cleaner Production elements of different kinds and different cost can be implemented in plating shops. Recovery of plating bath components and especially the direct recovery of plating baths play an important role in the cleaner technology applications. Obtained results in terms of the recovered material values (metals and other bath components), reduction of the operational costs, reduction of environmental pollution etc., as well as a significant reduction of rinsing water consumption are quite significant and enable minimisation of the environmental impact of plating production. At the same time the observed details of Cleaner Production show that plating quality level remains good and no trouble in plating bath maintenance occurs. 
64 Waste Management and the Environment III

\section{References}

[1] United Nations Environment Programme. Division of Technology, Industry and Economics. http://www.unep.org.

[2] Council Directive 96/61/EC of 24 September 1996 concerning integrated pollution prevention and control. Official Journal of European Communities, L257, 39, pp.15, 1996.

[3] EIPPC Bureau. Reference Document on Best Available Techniques for the Surface Treatment of Metals and Plastics. Dated September 2005. http://eipccb.jrc.es/pages/Fmembers.htm. 